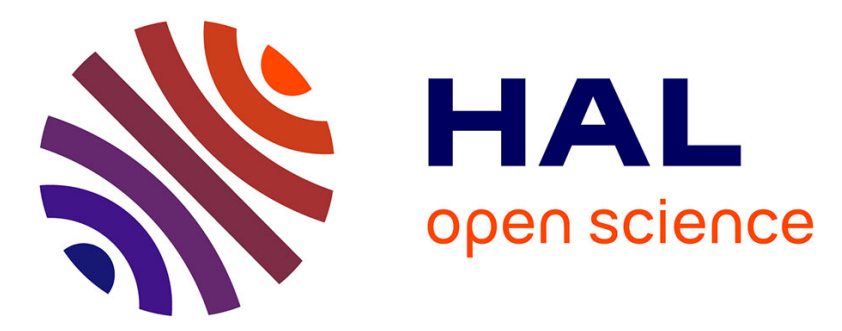

\title{
NF-kappaB inhibition improves the sensitivity of human glioblastoma cells to 5-aminolevulinic acid-based photodynamic therapy
}

Isabelle Coupienne Isabelle Coupienne, Sébastien Bontems, Michael Dewaele, Noemi Rubio, Yvette Habraken, Simone Fulda, Patrizia Agostinis, Jacques

Piette

\section{To cite this version:}

Isabelle Coupienne Isabelle Coupienne, Sébastien Bontems, Michael Dewaele, Noemi Rubio, Yvette Habraken, et al.. NF-kappaB inhibition improves the sensitivity of human glioblastoma cells to 5aminolevulinic acid-based photodynamic therapy. Biochemical Pharmacology, 2011, 81 (5), pp.606. 10.1016/j.bcp.2010.12.015 . hal-00663405

\section{HAL Id: hal-00663405 https://hal.science/hal-00663405}

Submitted on 27 Jan 2012

HAL is a multi-disciplinary open access archive for the deposit and dissemination of scientific research documents, whether they are published or not. The documents may come from teaching and research institutions in France or abroad, or from public or private research centers.
L'archive ouverte pluridisciplinaire HAL, est destinée au dépôt et à la diffusion de documents scientifiques de niveau recherche, publiés ou non, émanant des établissements d'enseignement et de recherche français ou étrangers, des laboratoires publics ou privés. 


\section{Accepted Manuscript}

Title: NF-kappaB inhibition improves the sensitivity of human glioblastoma cells to 5-aminolevulinic acid-based photodynamic therapy

Authors: Isabelle Coupienne Isabelle Coupienne, Sébastien Bontems, Michael Dewaele, Noemi Rubio, Yvette Habraken,

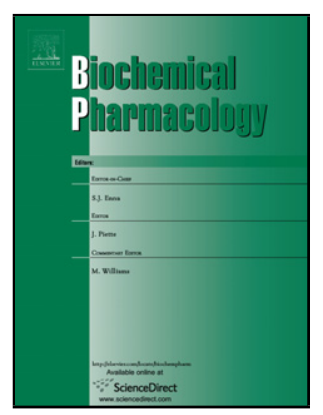

Simone Fulda, Patrizia Agostinis, Jacques Piette

PII:

S0006-2952(10)00880-4

DOI: doi:10.1016/j.bcp.2010.12.015

Reference: BCP 10781

To appear in: $\quad B C P$

Received date: $\quad 18-11-2010$

Revised date: $\quad 8-12-2010$

Accepted date: $\quad 14-12-2010$

Please cite this article as: Coupienne ICI, Bontems S, Dewaele M, Rubio N, Habraken Y, Fulda S, Agostinis P, Piette J, NF-kappaB inhibition improves the sensitivity of human glioblastoma cells to 5-aminolevulinic acid-based photodynamic therapy, Biochemical Pharmacology (2010), doi:10.1016/j.bcp.2010.12.015

This is a PDF file of an unedited manuscript that has been accepted for publication. As a service to our customers we are providing this early version of the manuscript. The manuscript will undergo copyediting, typesetting, and review of the resulting proof before it is published in its final form. Please note that during the production process errors may be discovered which could affect the content, and all legal disclaimers that apply to the journal pertain. 


\title{
NF-kappaB inhibition improves the sensitivity of human glioblastoma cells to 5-aminolevulinic acid-based photodynamic therapy
}

Isabelle Coupienne Isabelle Coupienne 1, Sébastien Bontems 1, Michael Dewaele 3, Noemi Rubio 1,3, Yvette Habraken 1, Simone Fulda 2, Patrizia Agostinis 3, Jacques Piette 1

1 Virology and Immunology Unit, GIGA-R, GIGA B34, University of Liège, Belgium

2 Institute for Experimental Cancer Research in Pediatrics, Goethe-University, Frankfurt, Germany.

${ }^{3}$ Cell Death Research and Therapy Laboratory, Department of Molecular Cell Biology, Faculty of Medicine, Catholic University of Leuven, Belgium

Running title : NF-KB inhibition improves glioblastomas' sensitivity to PDT

\begin{abstract}
Abbreviations list : 5-ALA, 5-aminolevulinic acid; BCL2, B-cell lymphoma 2; C-FLIP, Cellular FLICE-inhibitory protein ; EMSA, Electrophoretic mobility shift assay ; IAP, inhbitor of apoptosis ; $\mid \kappa B$, inhibitory $\kappa B$; LDH, lactate dehydrogenase ; LTR, long terminal repeat ; mTOR, mammalian target of rapamycin ; NF- $\mathrm{kB}$, nuclear factor kappa B ; PDD, photodiagnosis ; PDT, photodynamic therapy; PI, propidium iodide ; PPIX, protoporphyrin IX ; ROS, reactive oxygen species ; SR, IKB $\alpha$ super-repressor ; Tunel, terminal deoxynucleotidyl transferase dUTP nick end labeling ; XIAP, X-linked inhibitor of apoptosis
\end{abstract}

Corresponding author : Jacques Piette, laboratory of Virology and Immunology, GIGAResearch, 1, avenue de l'Hopital, 4000 Liège, Belgium, E-mail : jpiette@ulg.ac.be 


\section{Abstract}

Glioblastoma constitute the most frequent and deadliest brain tumors of astrocytic origin. They are very resistant to all current therapies and are associated with a huge rate of recurrence. In most cases, this type of tumor is characterized by a constitutive activation of the nuclear factor-kappaB (NF-kB). This factor is known to be a key regulator of various physiological processes such as inflammation, immune response, cell growth or apoptosis. In the present study, we explored the role of NF-kB activation in the sensitivity of human glioblastoma cells to a treatment by 5-aminolevulinic acid (5-ALA)-based photodynamic therapy (PDT). 5-ALA is a physiological compound widely used in PDT as well as in tumor photodetection (PDD). Our results show that inhibition of NF-kB improves glioblastoma cell death in response to 5-ALA-PDT. We then studied the molecular mechanisms underlying the cell death induced by PDT combined or not with NF-kB inhibition. We found that apoptosis was induced by PDT but in an incomplete manner and that, unexpectedly, NF-kB inhibition reduced its level. Oppositely PDT mainly induces necrosis in glioblastoma cells and NF-KB is found to have anti-necrotic functions in this context. The autophagic flux was also enhanced as a result of 5-ALA-PDT and we demonstrate that stimulation of autophagy acts as a prosurvival mechanism confering protection against PDT-mediated necrosis. These data point out that 5-ALA-PDT has an interesting potential as a mean to treat glioblastoma and that inhibition of NF-kB renders glioblastoma cells more sensitive to the treatment.

Key words : Photodynamic therapy, NF-kB, Glioblastoma, Necrosis, Autophagy, Apoptosis 


\section{Introduction}

Glioblastoma are among the most frequent and deadliest brain tumors. Prognosis associated with this type of cancer is generally very poor and most patients die within a year after diagnosis despite extensive research and the use of multimodality treatments combining surgical resection, chemotherapy and radiotherapy [1,2]. In addition, it should be noted that pro-autophagic chemotherapeutic agents such as temozolomide allow to partly overcome glioblastoma's resistance to apoptosis and were shown to have beneficial effects on patients' survival [3].

Photodynamic therapy is a form of treatment whose efficiency relies on the production and release of highly reactive oxygen species (ROS) following the irradiation of a photosensitizer with visible light of appropriate wavelength [4, 5]. 5-aminolevulinic acid (5-ALA) is a physiological heme precursor widely used to photosensitize cells [6]. Non-photosensitive 5ALA is metabolized into photosensitive protoporphyrin IX (PPIX) inside cells' mitochondria. PPIX preferentially accumulates into cancer cells due to their ferrochelatase deficiency [7]. In addition, 5-ALA is already efficiently used in tumor photodetection, notably in the case of glioblastoma surgical resection [8-10]. Furthermore, the use of 5-ALA in the context of PDT constitutes a promising treatment as it has already been successfully used in the case of a non-resectable glioblastoma [11].

The nuclear factor $\kappa \mathrm{B}(\mathrm{NF}-\mathrm{kB})$ is a ubiquitously expressed transcription factor implicated in the regulation of many cellular processes such as immunity, apoptosis, angiogenesis and proliferation. The NF- $\mathrm{kB}$ consists in homo- or hetero-dimers of five proteins belonging to the Rel/NF-kB family (p50, p52, p65, RelB, c-Rel). Under basal conditions, it is sequestered in the cytoplasm by inhibitor proteins of the $I_{\kappa} B$ (Inhibitory $\kappa B$ ) family but it can be rapidly activated in response to diverse signals including pro-inflammatory cytokines, pathogen infection, receptor ligands or chemical agents [12]. The inhibitor protein then gets phosphorylated by the IKK complex and is degraded by the proteasome, allowing the nuclear translocation of the NF-kB. Once in the nucleus, it can activate the transcription of its target genes [13]. The 
constitutive activation of NF-kB was described in different type of cancer including leukemias, lymphomas [14, 15] and glioma [16-19].

Glioblastoma cells are characterized by a high resistance to pro-apoptotic stimuli.as a result of constitutive activation of the PI3K/Akt, the mTOR, or the NF-KB signaling pathways [20]. In particular, NF-kB is known to activate the transcription of anti-apoptotic factors such as clAPS, cellular FLICE-inhibitory protein (C-FLIP) and anti-apoptotic members of the BCL2 family like $\mathrm{A} 1 / \mathrm{BfI} 1$ and $\mathrm{BCL}-\mathrm{XL}_{\mathrm{L}}[21]$.

In this study, we examined the role of the constitutive activation of NF- $\mathrm{KB}$ in glioblastoma sensitivity to 5-ALA-PDT and explored the cell death mechanisms induced by this treatment in combination with NF- $\mathrm{KB}$ inhibition. We found that NF-kB plays a protective role against PDTinduced cell death and more particularly against necrosis whereas apoptosis was reduced by NF-kB inhibition. 5-ALA-PDT stimulated autophagy as well, which acted as a cytoprotective mechanism against PDT-induced necrosis and its inhibition further sensitized glioblastoma cells to necrotic cell death. 


\section{Material and Methods}

\subsection{Cell culture}

Human glioblastoma LN18 and U87 cell lines were a kind gift of Pierre Robe (CNCM, university of Liège, Belgium). T98G glioblastoma and cervix adenocarcinoma HeLa cell lines were obtained from the ATCC (Manassas, VA). LN18, U87 and T98G cells were grown in DMEM with 10\% fetal bovine serum and 100 units/ml penicillin/streptomycin (Gibco-Invitrogen, Grand Island, NY). HeLa cells were cultured in EMEM with $10 \%$ fetal bovine serum and $100-$ units $/ \mathrm{ml}$ penicillin/streptomycin. All cultures were maintained at $37^{\circ} \mathrm{C}$ in a $5 \% \mathrm{CO}_{2}$ humidified atmosphere.

\subsection{Reagents and antibodies}

BAY 11-7082, staurosporine, bafilomycin Al and Draq5 were purchased from Enzo Life Sciences (Plymouth Meeting, PA). Smac mimetic (BV6) was previously described [22]. 5aminolevulinic acid (5-ALA), propidium iodide and trypan blue solutions were from SigmaAldrich (St. Lovis, MO), TNF- $\alpha$ was from Peprotech (Rocky Hill, NJ). The following antibodies were used for western blot analysis: anti-Phospho-IKBa (S32/36) (\#9246), anti-p70 S6 Kinase (\#2708), anti-Phospho-p70 S6 Kinase (Thr389) (\#9206) (Cell Signaling Technology, Danvers,

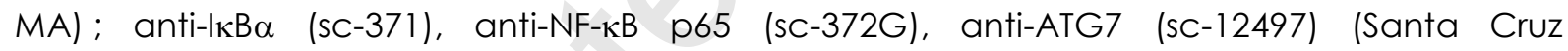
Biotechnology, (Santa Cruz,, CA); anti-XIAP (\#610717) (BD Biosciences, Erembodegem, Belgium) ; anti-Caspase-3 (ALX-804-305) (Enzo Life Sciences, Plymouth Meeting, PA) ; antiClAP-1 (\#AF8181) (R\&D Systems, Abingdon, United Kingdom); anti- $\beta$-Tubulin (T4026) and anti$\beta$-Actin (A4700) (Sigma-Aldrich, St. Lovis, MO).

\subsection{Generation of stable cell lines}

Retroviral pBabe-puro based constructs were used to generate stable cell lines. pBabeeGFFP-LC3 was obtained from J. Debnath [23] (Department of Pathology and Biomedical Sciences Graduate Program, San Francisco, CA) and the pBabe-Myc-IкB $\alpha(S 32 A / S 36 A)$ was a gift from Jean-François Peyron (INSERM U526, Nice, France). Stable pools of LN18, U87 and T98G expressing eGFP-LC3 and myc-IKB $\alpha$ (S32A/S36A) were obtained after infection and selection with puromycin ( $1 \mu \mathrm{g} / \mathrm{mL}$ ) (InvivoGen, San Diego, CA). 


\subsection{PDT treatment}

Cells were grown to near confluence. They were treated with $0.5 \mathrm{mM} 5$-ALA for 3 hours prior to irradiation with white light delivered by four fluorescent tubes (Aquarelle TLD-15W, Philips, Brussels, Belgium) with a fluence rate of $23.70 \mathrm{~W} / \mathrm{cm}^{2}$. NF-kB inhibition was performed using BAY-11 7082 added 30 min prior to irradiation at a concentration of $10 \mu \mathrm{M}$.

\section{5. siRNA transfection}

A pool of four siRNA duplexes targeting human ATG7 RNA were purchased from Dharmacon (Lafayette, CO). A control siRNA was purchased from Applied Biosystems (Carlsbad, CA). siRNAs were used at a concentration of $50 \mathrm{nM}$ and transfection was performed using calcium phosphate (ProFection® Mammalian Transfection System - Promega, Madison, WI).

\subsection{Western Blot analysis}

Western Blots were performed on total, cytoplasmic or nuclear cell extracts. Total cell lysates were obtained by resuspending cells in total lysis buffer $(50 \mathrm{mM}$ Tris- $\mathrm{HCl} \mathrm{pH} 7.5,150 \mathrm{mM} \mathrm{NaCl}$, 5 mM Na-pyrophosphate, 1\% Na-deoxycholate, 1\% NP-40, 1 mM PMSF, 3.3 mM NaF, 1 mM $\mathrm{Na}_{3} \mathrm{VO}_{4}, 25 \mathrm{mM} \beta$-glycerol-phosphate and Roche Complete ${ }^{\mathrm{TM}}$ protease inhibitor set from Roche Applied Science, Vilvoorde, Belgium). Cytoplasmic and nuclear extracts were obtained as described previously [24]. Briefly, cells were lysed in cytoplasmic buffer (10 mM Hepes-KOH pH 7.9, 2 mM MgCl $2,100 \mu$ EDTA, 10 mM KCl, 0.1\% Igepal, 1 mM DTT, 1 mM PMSF, 3.3 $\mathrm{mM} \mathrm{NaF}, 1 \mathrm{mM} \mathrm{Na} \mathrm{VO}_{4}, 25 \mathrm{mM}$-glycerol-phosphate, Roche Complete ${ }^{\mathrm{TM}}$ protease inhibitor set from Roche Applied Science, Vilvoorde, Belgium), incubated 20 min on ice and centrifuged for $5 \mathrm{~min}$ at $4000 \mathrm{~g}$. Supernatants contain cytoplasmic extracts and nuclear extracts were then obtained by lysing the pellet in nuclear buffer (50 mM Hepes-KOH pH 7.9, $50 \mathrm{mM} \mathrm{MgCl}, 100 \mu \mathrm{M}$ EDTA, $10 \mathrm{mM} \mathrm{KCl}, 300 \mathrm{mM} \mathrm{NaCl}, 1$ mM DTT, 1 mM PMSF, $3.3 \mathrm{mM} \mathrm{NaF}, 1$ $\mathrm{mM} \mathrm{Na}_{3} \mathrm{VO}_{4}, 25 \mathrm{mM} \beta$-glycerol-phosphate, Roche Complete ${ }^{\mathrm{TM}}$ protease inhibitor set from Roche Applied Science, Vilvoorde, Belgium). Equal amounts of protein extracts were resolved in $10 \%$ SDS-PAGE, transferred to a PVDF membrane (GE Healthcare, Munich, Germany) and incubated with correspondent antibody. The immune complexes were detected by enhanced chemiluminescence (GE Healthcare, Munich, Germany). Band quantification was carried out with the ImageQuant software (GE Healthcare, Munich, Germany). 


\subsection{Electrophoretic mobility shift assay (EMSA)}

To perform the electrophoretic mobility shift analysis, $5 \mu \mathrm{g}$ of nuclear protein extracts were incubated with a radioactive probe containing the NF-KB binding sequence present in the long terminal repeat (LTR) region of HIV-1 as described in [24].

\subsection{Cell survival}

Cell survival in response to the various treatments was assessed using trypan blue exclusion test. The survival of LN18 and U87 cells was measured in 6-well cell culture plates. Twenty-four hours after the indicated treatments, cells were trypsinized, collected in PBS and stained with trypan blue. Cells were then counted on a Thoma hemocytometer. Each experiment was performed in triplicate. Results are presented as the mean ratio ( \pm SD) between dyeincorporating and non-incorporating cells and are representative of three independent experiments.

\subsection{Apoptosis}

Caspase-3 activity was measured in vitro with the colorimetric CaspACETM Assay system (Promega, Madison, WI) according to the manufacturer's instructions. Experiments were conducted in triplicates. Data are presented as the mean caspase-3 activity induction ( \pm SD) and are representative of three independent experiments.

Terminal deoxynucleotidyl transferase dUTP nick end labeling (TUNEL) was performed using the DeadEnd Fluorometric TUNEL System (Promega, Madison, WI) according to the manufacturer's instructions, on cells grown on glass coverslips. Cell slides were analyzed on a Leica TCS SP2 confocal microscope (Leica, Wetzlar, Germany).

DNA laddering experiments were conducted with the Apoptotic DNA Ladder Kit (Roche Applied Science, Vilvoorde, Belgium) according to the manufacturer's protocol. Camptothecin-treated U937 cells' DNA used as a positive control for this experiment was provided in this kit.

\subsection{Necrosis}

Lactate dehydrogenase (LDH) release was measured in cells' supernatants at various time points after the indicated treatments using the CytoTox $96{ }^{\circledR}$ Non-Radioactive Cytotoxicity Assay (Promega, Madison, WI) on cells grown to 70-80\% confluence in 12-well culture plates. 
Experiments were conducted in triplicates. Data are presented as the mean lactate dehydrogenase release induction ( \pm SD) and are representative of at least three independent experiments.

Propidium iodide staining was performed on cells grown on glass coverslips. After the indicated treatments, cells were fixed with $4 \%$ paraformaldehyde for 10 min at room temperature. They were then incubated with $1 \mu \mathrm{g} / \mathrm{ml}$ propidium iodide for $15 \mathrm{~min}$ at room temperature in the dark. Cell slides were analyzed by confocal microscopy using the Leica TCS SP2 (Wetzlar, Germany).

\subsection{Quantification of eGFP-LC3 puncta}

LN18 cells stably expressing eGFP-LC3 were grown to near confluence and treated as indicated. Autophagy was quantified by counting the percentage of cells presenting an accumulation of EGFP-LC3 in vacuoles using a FSX-100 fluorescence microscope (Olympus, Hamburg, Germany). A minimum of 200 cells were considered for each analysis and experiments were performed three times independently. 


\section{Results}

\subsection{The NF- $k B$ pathway is constitutively activated in glioblastoma cells and can be further activated in response to 5-ALA-PDT}

To study the role of NF- $\mathrm{kB}$ in glioblastoma cell death by 5-ALA-PDT, we generated stable cell lines expressing the super-repressor form of the NF- $\kappa B$ inhibitor $\mid \kappa B \alpha$, namely $\left.\right|_{\kappa} B \alpha S R \quad\left(I_{\kappa} B \alpha\right.$ S32A/S36A). Indeed, we were able to observe by western blot both endogenous $1 \kappa B \alpha$ and the IKB $\alpha$ SR in three glioblastoma cell lines such as LN18 SR, T98G SR and U87 SR but only the first one was degraded following exposure to TNF- $\alpha$ (Fig. 1A). Furthermore, we noticed that the level of $I_{\kappa} B \alpha$ phosphorylation on S32 and S36 $\left(\mathrm{P}-\left.\right|_{\kappa} B \alpha\right)$ constitutively present and induced by the TNF- $\alpha$ treatment was profoundly decreased in SR cells compared to WT cells (Fig. 1A). NF$\kappa B$ activity was also detected in the nucleus. LN18 cells show a constitutive NF- $\mathrm{KB}$ binding activity, which is strongly increased by a TNF- $\alpha$ treatment (Fig. 1B, left). On the other hand, no binding was detected in LN18 SR, even after TNF- $\alpha$ challenge. NF-kB p65 subunit could also be detected in the nucleus of wild type T98G and U87 cells and an increased nuclear amount could be observed after TNF- $\alpha$ addition whereas no p65 could be encountered in the nucleus of untreated SR cells (Fig.1B). After TNF- $\alpha$ treatment, only a slight amount was found in T98G SR cells' nucleus (Fig. 1B, right). The different glioblastoma cell lines we used show a constitutive NF-KB activity, which is in agreement with previous reports [16-19]. Moreover, they can also undergo a further activation not only in response to TNF- $\alpha$ but also in response to a 5-ALA-PDT treatment (Fig. 1C). In addition, NF-kB binding on the probe could be efficiently blocked at $1 \mathrm{~h}$ and $4 \mathrm{~h}$ post-irradiation using BAY-11 7082, a pharmacological inhibitor of NF-kB targeting the kinase activity of the IKK complex's $\beta$ subunit. A p65 western blot performed on nuclear extracts confirmed the results obtained by EMSA and showed that 5-ALA-PDT induced a BAY-inhibitable nuclear translocation of NF-kB, whereas no p65 nuclear accumulation was seen in SR cells after PDT (data not shown).

\subsection{NF-KB inhibition potentiates 5-ALA-PDT-induced cell death in glioblastoma}


After having shown that 5-ALA-PDT mediates a further NF-kB activation in different

glioblastoma cell lines we evaluated the role of this transcription factor in PDT-mediated cell death.

Our results indicate that LN18 glioblastoma cells were sensitive to a 5-ALA-PDT treatment. Interestingly, the level of death due to 5-ALA-PDT in LN18 cells was found to be significantly higher in cells pre-treated with the IKK complex inhibitor BAY and in cells expressing the super repressor form of $I_{\kappa} B \alpha$ (Fig. 2, top panel). The same phenomenon could be observed in U87 cells where survival was sharply decreased after 5-ALA-PDT when NF-кB was inhibited either by treatment with BAY or by the presence of the un-degradable form of IKB $\alpha$ (SR cell lines)(Fig.2B lower panel). However, U87 cells proved to be more sensitive to 5-ALA-PDT than LN18 cells, so the light doses had to be reduced accordingly. A similar cell sensitivity to NF-KB inhibition was also observed in T98G cells (data not shown). We did not observe any significant difference in cell survival between non-irradiated untreated cells and nonirradiated BAY-treated cells. Altogether, these data suggest that constitutive and PDTinduced NF-KB activation have a key role in the protection against cell death.

\subsection{NF- $\kappa B$ is pro-apoptotic in the context of glioblastoma treatment by 5-ALA-PDT}

As a previous report suggested that glioblastoma U87 cells underwent apoptosis in response to 5-ALA-PDT [25] and NF-kB has a well-known ability to suppress apoptosis [21, 26], we wondered whether NF-KB also protected glioblastoma cells during PDT. However, unexpectedly, NF-kB inhibition resulted in a decreased cleavage and activity of caspase-3 (Fig. 3A, left). This cleavage actually turned out to be very weak compared to a positive control like staurosporine-treated HeLa cells. After quantification, we found that caspase-3 cleavage was 30 times greater in this positive control than in 5-ALA-PDT-treated LN18 cells at 4 hours post-irradiation (Fig. 3A, right). We then looked at a later apoptotic step and performed a TUNEL assay experiment, which revealed that none of the PDT-treated cells' nucleus displayed fragmented DNA (Fig. 3B). We also examined DNA laddering not only after PDT but also in response to other apoptosis inducers, such as daunomycin and staurosporine. As shown in Fig. $3 \mathrm{C}$ we failed to detect DNA laddering in all these conditions, thus indicating 
that LN18 cells present a defect in apoptosis completion. Seeking a possible explanation for this inability to properly induce apoptosis, we analyzed the expression of IAPs, which are key endogenous caspase inhibitors [27]. We also tested whether a Smac mimetic (BV6) could, along with PDT, increase the level of apoptosis in LN18 cells. BV6 alone was able to induce caspase-3 processing along with a reduction in CIAP-1 and to a lesser extent of XIAP expression levels, thus confirming the relevance of these IAPs in increasing the threshold for caspase activation in these cells. Surprisingly, while the treatment combining Smac mimetic and PDT resulted in an increased caspase-3 cleavage compared to PDT alone, this induction was remarkably weaker than the sensitization obtained with BV6 alone, despite the weaker CIAP-1 and XIAP levels observed (Fig. 3D). This suggests that PDT in glioblastoma cells further suppresses caspase signaling, in spite of a rapid reduction of IAPs levels.

\subsection{Death by necrosis due to 5-ALA-PDT is increased when NF-KB is inhibited in glioblastoma cells}

The necrotic pathway was then examined by measurement of lactate dehydrogenase (LDH), which leaks out into the extracellular medium upon loss of plasma membrane integrity occurring rapidly during necrotic cell death. Our data show that necrosis due to PDT is significantly higher in glioblastoma cells in which the NF-kB pathway is inhibited as soon as $1 \mathrm{~h}$ post irradiation (Fig. 4A). To confirm these results, cells were subjected to a propidium iodide (PI) staining, which showed that many more cells were stained by PI consequently to the 5ALA-PDT treatment when the NF-kB was inhibited (Fig. 4B). Taken together, these data establish that NF-kB could have an anti-necrotic role in glioblastoma in the context of 5-ALAPDT treatments.

\subsection{5-ALA-PDT leads to an increased autophagic flux in glioblastoma}

Autophagy was previously shown to be induced by 5-ALA-PDT in PC 12 and CL1-0 cancer cell lines [28]. Therefore, we decided to examine the activation of this pathway in our glioblastoma cells. Our findings reveal that 5-ALA-PDT effectively led to a time-dependent conversion of LC3-I into its autophagosome-bound form named LC3-II, which is a hallmark of autophagy $[29,30]$, in LN18 cells (Fig. 5A, top). Of importance, the conversion of LC3-I into 
LC3-II increased with time after irradiation up to $4 \mathrm{~h}$ to be reversed at $24 \mathrm{~h}$ post-irradiation. Another commonly used method to monitor autophagy is the visualization of LC3's cellular distribution by microscopy. Mainly diffused under basal conditions, LC3 re-localizes to the autophagosomes and appears punctuated during autophagy stimulation. These microscopy studies were made in LN18 cells stably expressing eGFP-tagged LC3. In untreated cells, we observed that GFP fluorescence was mainly diffuse whereas it became punctuated after 5ALA-PDT treatment (Fig. 5A, middle). In non-irradiated cells the percentage of cells displaying eGFP-LC3 puncta was significantly higher especially at $2 \mathrm{~h}(30 \%)$ and $4 \mathrm{~h}(35 \%)$ post-irradiation. Afterwards, at $24 \mathrm{~h}$ pi, this ratio goes down and reaches $17 \%$ (5A, bottom). An increase in LC3Il level can actually reflect two opposite situations: it can either be the sign of an enhanced complete autophagic flux or reveal an inhibited clearance of autophagosomes, resulting from an incomplete autophagic process. To discriminate between these two phenomena, we treated our glioblastoma cells with bafilomycin Al, which inhibits a late autophagic step, i.e. the fusion beween autophagosomes and lysosomes. Use of bafilomycin Al resulted in an increased LC3-II level in both irradiated and un-irradiated cells, proving that 5-ALA-PDT indeed leads to a complete autophagic process (Fig.5B).

Altogether, these results indicate that along with the induction of cell death, 5-ALA-PDT induces an enhancement of autophagy in glioblastoma.

We then addressed the question whether NF-kB played a role in autophagy induction in response to PDT. The results indicated that the level of LC3-II is higher in LN18 pretreated with the IKK inhibitor BAY both in irradiated and un-irradiated cells while the one observed in SR cells is similar to what is seen in WT cells (Fig. 5C). Consistently, the level of p70S6K phosphorylation on Thr389 (a target of the mammalian Target Of Rapamycin - mTOR) decreased after PDT. Furthermore, inhibition of the mTOR- p70S6K pathway was more pronounced and persistent in BAY-treated cells as compared to wild type cells that were not treated with BAY and to IKB $\alpha S R$-expressing cells (Fig.5B).

\subsection{Autophagy protects glioblastoma cells against 5-ALA-PDT-induced necrosis}


Since autophagy is a process able to promote either cell survival or cell death (27), we decided to knock down ATG7 in order to distinguish between these two opposite outcomes. SiRNAs against ATG7 were transfected in LN18 cells and western blot analysis demonstrated that the level of ATG7 in transfected cells was strongly decreased compared to the level observed in untransfected cells or cells transfected with an irrelevant siRNA (Fg. 6A, left). ATG7 knock-down also severely impaired LC3 conversion upon PDT (Fig. 6, right). Necrosis in response to 5-ALA-PDT was then examined. Our lactate dehydrogenase assay results show that LN18 transfected with the ATG7 siRNA are significantly more sensitive to PDT-induced necrosis (Fig. 6B, top). This was again confirmed by a PI staining, clearly showing that many more cells had taken up PI after PDT when autophagy is repressed (Fig. 6B, bottom).

Thus, these data indicate that siRNA-based knockdown of ATG7 and BAY inhibitor can each provoke an enhanced necrosis rate in glioblastoma in response to 5-ALA-PDT but the question remained whether autophagy and NF- $\kappa B$ inhibition could have greater effects when used together. Indeed, cells transfected with the ATG7 siRNA and treated with BAY prior to irradiation appeared significantly more sensitive to PDT-induced necrosis at 4 h post-irradiation than those having undergone only one of the two treatments (Fig. 6C). We then wondered if, like necrosis, apoptosis would be increased in autophagy-impaired cells in response to PDT. Interestingly, no difference in the level of caspase-3 cleavage or in its enzymatic activity could be observed after 5-ALA-PDT between control siRNA and ATG7 siRNA-transfected cells (Fig. 6D, top left and bottom). Efficiency of ATG7 depletion was verified by western blot (Fig. 6D, right). 


\section{Discussion}

The present study shows that human glioblastoma cells present a constitutive activation of the NF-KB pathway, further increased after a 5-ALA-PDT treatment. We demonstrate that, in the context of a treatment by 5-ALA-PDT on glioblastoma cells, (i) inhibition of NF-kB significantly enhances cell death, (ii) NF-kB is pro-apoptotic but glioblastoma cells undergo an incomplete apoptotic process, (iii) NF-kB is anti-necrotic and (iv) autophagy is induced as a pro-survival mechanism.

Consistent with a previous report [25], treatment by 5-ALA-PDT induced cell death and apoptosis in glioblastoma cells. However, oppositely to the results shown in this paper, we do observe an increased activity of NF-kB rather than a down-regulation by PDT. This discrepancy probably comes from the methods used to study the nuclear translocation of p65. NF-kB was previously shown to be activated by ROS and particularly by singlet oxygen [31], which was shown to be the main ROS produced by 5-ALA photosensitization, therefore reinforcing our conclusions.

Evasion of apoptosis is commonly observed in cancer cells [32] and glioblastoma are no exception to this rule $[20,33]$. They were shown to escape apoptosis by (i) over-expressing anti-apoptotic proteins of the BCL-2 family such as BCL-2 and BCL-XL, but down-regulating the pro-apoptic Bax [34], (ii) expressing the BCL2-like 12 protein (BCL2L12), an inhibitor of caspase-3 and caspase-7 [35, 36] and (iii) expressing high levels of IAP proteins [37, 38]. Consequently, it is not surprising that 5-ALA-PDT induces such a weak level of apoptosis in these cells. In an attempt to restore apoptosis competency, we used a Smac mimetic, a small IAP antagonist [22]. Unexpectedly, the combination between Smac mimetics and PDT caused a weaker caspase-3 cleavage compared to Smac mimetic treatment alone, although it somehow stimulated caspase-3 processing after PDT treatment. This suggests that, beside displaying intrinsic defects in the apoptotic machinery, PDT by itself may negatively interfere with caspase signaling in these cells, probably through a ROS-mediated inhibition of caspases, as already reported [39]. In this case, cells would preferentially undergo necrosis in response to PDT because cells in which caspases cannot be efficiently activated often 
undergo necrosis in response to apoptotic stimuli [40]. More surprising is the fact that NF-kB is pro-apoptotic in 5-ALA-PDT-treated glioblastoma. NF-KB is generally considered as antiapoptotic but it has already been reported to be pro-apoptotic in some situations [41]. NF-kB was demonstrated to induce apoptosis mainly by transcriptionally upregulating proapoptotic target genes like those encoding pro-apoptotic BCL-2 family members, TRAIL, Fas and p53 [41]. Furthermore, it was recently shown to promote DNA damage and apoptosis in response to DNA intercalators [42]. As glioblastoma over-express anti-apoptotic BCL-2 family proteins to ensure apoptosis resistance, it is very unlikely that those genes would be upregulated by NF- $\mathrm{KB}$ since no DNA damage is inflicted by 5-ALA-PDT [5]. Consequently, there is little chance that NF-KB exerts its positive regulation on apoptosis through a p53-dependent mechanism. However, even in the absence of NF-kB inhibition, apoptosis is very poorly induced in glioblastoma cells and contributes far less to PDT-induced cell death than necrosis.

Unlike apoptosis, necrosis was enhanced by NF-kB inhibition after treatment by PDT. So, in this situation, NF-kB fulfils an anti-necrotic role. Indeed, NF-kB was shown to participate to ROS elimination by inducing the transcription of antioxidant enzymes $[43,44]$. If that was the case in response to PDT, it would allow cells to temper the resulting ROS-induced cellular damage. However, this is obviously not the only mechanism by which NF-kB could mediate necrosis inhibition because this effect can be observed in BAY-treated cells as soon as $1 \mathrm{~h}$ postirradiation. Not much is known yet about the precise mechanisms by which necrosis is regulated but the RIP3 kinase has recently been demonstrated as a major effector of this cell death pathway, triggering cell death by leading to the over-generation of ROS in the mitochondria $[45,46]$. Therefore, it is possible that NF-kB somehow interferes with RIP3dependent necrosis induction. Further studies are definitely necessary to learn whether or not RIP3 is implicated in PDT-induced necrosis and, if so, what could be the role of NF- $\mathrm{KB}$ in this process.

Autophagy is another pathway activated in glioblastoma in response to 5-ALA-PDT. As already indicated by several studies examining the role of autophagy in cancer, this process 
can be a pro-death [47] as well as a pro-survival pathway [48] (reviewed in [49]). Inducing autophagy in glioblastoma to overcome their resistance to apoptosis was proven efficient both at experimental [50] and clinical levels [2,3]. Yet, in the case of 5-ALA-PDT, our data reveal that autophagy rather plays a protective role against necrosis. Since autophagy is a quality control mechanism involved in the removal of ROS-damaged proteins and organelles [51], it is plausible that reducing ROS damage by autophagic degradation limits necrotic cell death in our paradigm. Additionally, it is possible that autophagy stimulation by 5-ALA-PDT leads to the removal of a factor (a molecule or an organelle) that is required to promote necrosis.

Furthermore, we noticed that inhibition of the IKK complex (and more particularly of the IKK $\beta$ kinase), but not expression of $I_{\kappa} B \alpha S R$, led to a further increased autophagic flux. These results are consistent with previous reports indicating that there is an interaction and a reciprocal activation between the IKK complex and mTOR as a part of TORCl complex [52]. In another report, IKK $\beta$ was also shown to induce the activation of mTOR through the phosphorylation of TSC1 [53]. Knowing that mTOR activity inhibits autophagy, this explains how inhibition of IKK $\beta$ leads to an increased autophagy.

Given that and despite the use of available treatments, glioblastoma patients' survival rarely exceeds one year. From our results, we can conclude that, in addition to being used in tumor photodetection, 5-ALA has a real therapeutic potential in the context of PDT whether it is used alone as in the case of non-resectable tumors or in combination with surgery to irradiate the resection margins and limit recurrence. One main advantage of 5-ALA-PDT is that PPIX accumulates preferentially in tumor cells so the damage to the surrounding healthy brain tissues is limited compared to other methods like chemotherapy. From the data shown above its efficiency could be increased if this therapy is used along with pharmacological NF-kB inhibitors to improve cell killing and with inhibitors of autophagy like chloroquine to prevent cells from recovering using the autophagic process. However, our conclusions rely on in vitro experiments and in vivo studies are necessary to confirm that glioblastoma cells similarly respond to 5-ALA-PDT and inhibition of NF- $\mathrm{KB}$ and that patients could actually benefit from 
this combined treatment.

1

2

3

4

5

6

7

8

10

11

12

13

14

15

16

17

18

19

20

21

22

23

24

25

26

27

28

29

30

31

32

33

34

35

36

37

38

39

40

41

42

43

44

45

46

47

48

49

50

51

52

53

54

55

56

57

58

59

60

61

62

63

64 


\section{Acknowledgements}

We thank Dr. P. Robe for the LN18 and U87 cell lines, Dr J. Debnath for the pBabe-eGFP-LC3

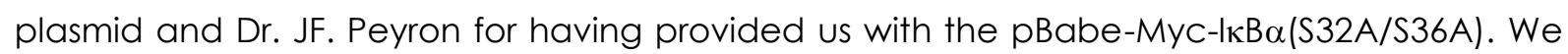
acknowledge Kerry Zobel, Kurt Deshayes and Domagoj Vucic for providing the BV6 Smac mimetic. We also would like to thank N. Renotte and C. Lassence for technical assistance. IC is PhD student supported by the FRIA (Brussels, Belgium). JP and YH are Research Director and Senior Research Associate at the FNRS (Brussels, Belgium), respectively. NR is a post-doctoral fellow supported by F.R.S.-FNRS grant F/5/4/5-MCF/KP. This work was supported by grants from the FNRS and from the Inter-University Attraction Poles (IAP6/18, Brussels, Belgium) and by OT/06/49 of the K.U.Leuven to PA. MD is a fellow of the Institute for the Promotion of Innovation through Science and Technology in Flanders (IWT-Vlaanderen). 


\section{References}

[1] Louis DN, Ohgaki H, Wiestler OD, Cavenee WK, Burger PC, Jouvet A, et al. The 2007 WHO classification of tumours of the central nervous system. Acta Neuropathol 2007;1 14:97-109.

[2] Stupp R, Hegi ME, Mason WP, van den Bent MJ, Taphoorn MJ, Janzer RC, et al. Effects of radiotherapy with concomitant and adjuvant temozolomide versus radiotherapy alone on survival in glioblastoma in a randomised phase III study: 5-year analysis of the EORTC-NCIC trial. Lancet Oncol 2009;10:459-66.

[3] Lefranc F, Facchini V, Kiss R. Proautophagic drugs: a novel means to combat apoptosis-resistant cancers, with a special emphasis on glioblastomas. Oncologist 2007;12:1395-403.

[4] Dolmans DE, Fukumura D, Jain RK. Photodynamic therapy for cancer. Nat Rev Cancer 2003;3:380-7.

[5] Dougherty TJ, Gomer CJ, Henderson BW, Jori G, Kessel D, Korbelik M, et al. Photodynamic therapy. J Natl Cancer Inst 1998;90:889-905.

[6] Peng Q, Berg K, Moan J, Kongshaug M, Nesland JM. 5-Aminolevulinic acid-based photodynamic therapy: principles and experimental research. Photochem Photobiol 1997;65:235-51

[7] Ongari Y, Nakayasu Y, Kitajima S, Sawamoto M, Mori H, Shimokawa O, et al. Mechanisms involved in delta-aminolevulinic acid (ALA)-induced photosensitivity of tumor cells: relation of ferrochelatase and uptake of ALA to the accumulation of protoporphyrin. Biochem Pharmacol 2005;71:42-9.

[8] Nabavi A, Thurm H, Zountsas B, Pietsch T, Lanfermann H, Pichlmeier U, et al. Fiveaminolevulinic acid for fluorescence-guided resection of recurrent malignant gliomas: a phase ii study. Neurosurgery 2009;65:1070-6; discussion 6-7. 
[9] Stummer W, Pichlmeier U, Meinel T, Wiestler OD, Zanella F, Reulen HJ. Fluorescenceguided surgery with 5-aminolevulinic acid for resection of malignant glioma: a randomised controlled multicentre phase III trial. Lancet Oncol 2006;7:392-401.

[10] Kostron H. Photodynamic diagnosis and therapy and the brain. Methods Mol Biol $2010 ; 635: 261-80$

[11] Stummer W, Beck T, Beyer W, Mehrkens JH, Obermeier A, Etminan N, et al. Longsustaining response in a patient with non-resectable, distant recurrence of glioblastoma multiforme treated by interstitial photodynamic therapy using 5-ALA: case report. J Neurooncol 2008;87:103-9.

[12] Pahl HL. Activators and target genes of Rel/NF-kappaB transcription factors. Oncogene 1999;18:6853-66.

[13] Hayden MS, Ghosh S. Signaling to NF-kappaB. Genes Dev 2004;18:2195-224.

[14] Rayet B, Gelinas C. Aberrant rel/nfkb genes and activity in human cancer. Oncogene 1999;18:6938-47.

[15] Bargou RC, Leng C, Krappmann D, Emmerich F, Mapara MY, Bommert K, et al. Highlevel nuclear NF-kappa B and Oct-2 is a common feature of cultured Hodgkin/ReedSternberg cells. Blood 1996;87:4340-7.

[16] Raychaudhuri B, Han Y, LU T, Vogelbaum MA. Aberrant constitutive activation of nuclear factor kappaB in glioblastoma multiforme drives invasive phenotype. J Neurooncol 2007.

[17] Ansari SA, Safak M, Del Valle L, Enam S, Amini S, Khalili K. Cell cycle regulation of NFkappa b-binding activity in cells from human glioblastomas. Exp Cell Res 2001;265:22133. 
[18] Brown RE, Law A. Morphoproteomic demonstration of constitutive nuclear factorkappaB activation in glioblastoma multiforme with genomic correlates and therapeutic implications. Ann Clin Lab Sci 2006;36:421-6.

[19] Robe PA, Bentires-Alj M, Bonif M, Rogister B, Deprez M, Haddada H, et al. In vitro and in vivo activity of the nuclear factor-kappaB inhibitor sulfasalazine in human glioblastomas. Clin Cancer Res 2004;10:5595-603.

[20] Lefranc F, Brotchi J, Kiss R. Possible future issues in the treatment of glioblastomas: special emphasis on cell migration and the resistance of migrating glioblastoma cells to apoptosis. J Clin Oncol 2005;23:241 1-22.

[21] Karin M, Cao Y, Greten FR, Li ZW. NF-kappaB in cancer: from innocent bystander to major culprit. Nat Rev Cancer 2002;2:301-10.

[22] Varfolomeev E, Blankenship JW, Wayson SM, Fedorova AV, Kayagaki N, Garg P, et al. IAP antagonists induce autoubiquitination of C-IAPs, NF-kappaB activation, and TNFalpha-dependent apoptosis. Cell 2007;131:669-81.

[23] Fung C, Lock R, Gao S, Salas E, Debnath J. Induction of autophagy during extracellular matrix detachment promotes cell survival. Mol Biol Cell 2008;19:797-806.

[24] Coupienne I, Piette J, Bontems S. How to monitor NF-kappaB activation after photodynamic therapy. Methods Mol Biol 2010;635:79-95.

[25] Karmakar S, Banik NL, Patel SJ, Ray SK. 5-Aminolevulinic acid-based photodynamic therapy suppressed survival factors and activated proteases for apoptosis in human glioblastoma U87MG cells. Neurosci Lett 2007:415:242-7.

[26] Karin M, Lin A. NF-kappaB at the crossroads of life and death. Nat Immunol 2002;3:2217. 
[27] Gyrd-Hansen M, Meier P. IAPs: from caspase inhibitors to modulators of NF-kappaB, inflammation and cancer. Nat Rev Cancer 2010;10:561-74.

[28] Ji HT, Chien LT, Lin YH, Chien HF, Chen CT. 5-ALA mediated photodynamic therapy induces autophagic cell death via AMP-activated protein kinase. Mol Cancer 2010;9:91.

[29] Kabeya Y, Mizushima N, Ueno T, Yamamoto A, Kirisako T, Noda T, et al. LC3, a mammalian homologue of yeast Apg8p, is localized in autophagosome membranes after processing. EMBO J 2000;19:5720-8.

[30] Klionsky DJ, Abeliovich H, Agostinis P, Agrawal DK, Aliev G, Askew DS, et al. Guidelines for the use and interpretation of assays for monitoring autophagy in higher eukaryotes. Autophagy 2008;4:151-75.

[31] Volanti C, Matroule JY, Piette J. Involvement of oxidative stress in NF-kappaB activation in endothelial cells treated by photodynamic therapy. Photochem Photobiol 2002;75:36-45.

[32] Hanahan D, Weinberg RA. The hallmarks of cancer. Cell 2000;100:57-70.

[33] Krakstad C, Chekenya M. Survival signalling and apoptosis resistance in glioblastomas: opportunities for targeted therapeutics. Mol Cancer 2010:9:135.

[34] Strik H, Deininger M, Streffer J, Grote E, Wickboldt J, Dichgans J, et al. BCL-2 family protein expression in initial and recurrent glioblastomas: modulation by radiochemotherapy. J Neurol Neurosurg Psychiatry 1999;67:763-8.

[35] Stegh AH, Chin L, Lovis DN, DePinho RA. What drives intense apoptosis resistance and propensity for necrosis in glioblastoma? A role for Bcl2L12 as a multifunctional cell death regulator. Cell Cycle 2008;7:2833-9. 
[36] Stegh AH, Kim H, Bachoo RM, Forloney KL, Zhang J, Schulze H, et al. Bcl2L12 inhibits post-mitochondrial apoptosis signaling in glioblastoma. Genes Dev 2007;21:98-111.

[37] Angileri FF, Aguennouz M, Conti A, La Torre D, Cardali S, Crupi R, et al. Nuclear factorkappaB activation and differential expression of survivin and BCl-2 in human grade 2-4 astrocytomas. Cancer 2008;1 12:2258-66.

[38] Wagenknecht B, Glaser T, Naumann U, Kugler S, Isenmann S, Bahr M, et al. Expression and biological activity of X-linked inhibitor of apoptosis (XIAP) in human malignant glioma. Cell Death Differ 1999;6:370-6.

[39] $D \cup J Q, W \cup ~ J$, Zhang $H J$, Zhang $Y H$, Qiu BY, WU F, et al. Isoquinoline-1,3,4-trione derivatives inactivate caspase-3 by generation of reactive oxygen species. J Biol Chem 2008:283:30205-15.

[40] Vercammen D, Brouckaert G, Denecker G, Van de Craen M, Declerca W, Fiers W, et al. Dual signaling of the Fas receptor: initiation of both apoptotic and necrotic cell death pathways. J Exp Med 1998;188:919-30.

[41] Radhakrishnan SK, Kamalakaran S. Pro-apoptotic role of NF-kappaB: implications for cancer therapy. Biochim Biophys Acta 2006;1766:53-62.

[42] Karl S, Pritschow Y, Volcic M, Hacker S, Baumann B, Wiesmuller L, et al. Identification of a novel pro-apopotic function of NF-kappaB in the DNA damage response. J Cell Mol Med 2009;13:4239-56.

[43] Pham CG, Bubici C, Zazzeroni F, Papa S, Jones J, Alvarez K, et al. Ferritin heavy chain upregulation by NF-kappaB inhibits TNFalpha-induced apoptosis by suppressing reactive oxygen species. Cell 2004;119:529-42.

[44] Sakon S, Xue X, Takekawa M, Sasazuki T, Okazaki T, Kojima Y, et al. NF-kappaB inhibits TNF-induced accumulation of ROS that mediate prolonged MAPK activation and necrotic cell death. EMBO J 2003;22:3898-909. 
[45] He S, Wang L, Miao L, Wang T, Du F, Zhao L, et al. Receptor interacting protein kinase3 determines cellular necrotic response to TNF-alpha. Cell 2009;137:1 100-11.

[46] Galluzzi L, Kepp O, Kroemer G. RIP kinases initiate programmed necrosis. J Mol Cell Biol 2009;1:8-10.

[47] Azad MB, Chen Y, Henson ES, Cizeau J, McMillan-Ward E, Israels SJ, et al. Hypoxia induces autophagic cell death in apoptosis-competent cells through a mechanism involving BNIP3. Autophagy 2008;4:195-204.

[48] Apel A, Herr I, Schwarz H, Rodemann HP, Mayer A. Blocked autophagy sensitizes resistant carcinoma cells to radiation therapy. Cancer Res 2008;68:1485-94.

[49] Codogno P, Meijer AJ. Autophagy and signaling: their role in cell survival and cell death. Cell Death Differ 2005;12 Suppl 2:1509-18.

[50] Lefranc F, Mijatovic T, Kondo Y, Sauvage S, Roland I, Debeir O, et al. Targeting the alpha 1 subunit of the sodium pump to combat glioblastoma cells. Neurosurgery 2008;62:211-21; discussion 21-2.

[51] Dewaele M, Maes H, Agostinis P. ROS-mediated mechanisms of autophagy stimulation and their relevance in cancer therapy. Autophagy 2010;6:838-54.

[52] Dan HC, Cooper MJ, Cogswell PC, Duncan JA, Ting JP, Baldwin AS. Akt-dependent regulation of NF-\{kappa\}B is controlled by mTOR and Raptor in association with IKK. Genes Dev 2008;22:1490-500.

[53] Lee DF, Kuo HP, Chen CT, Hsu JM, Chou CK, Wei Y, et al. IKK beta suppression of TSC1 links inflammation and tumor angiogenesis via the mTOR pathway. Cell 2007;130:44055. 


\section{Figure captions}

Fig. 1 : Constitutive NF- $\kappa$ B activity in different glioblastoma cell lines. (A) The expression of $I_{K} B \alpha S R$ and the phosphorylation status of $I_{\kappa} B \alpha$ were assessed in cytoplasmic extracts of LN18 WT and LN18 SR cells (left) as well as in T98G, T98G SR, U87 and U87SR cell lines (right) by western blotting . Cells were either left untreated or were treated with $500 \mathrm{U} / \mathrm{ml}$ of TNF- $\alpha$ for 30 min. (B) NF-kB DNA binding activity was studied by EMSA and was performed on LN18 WT and LN18 SR nuclear extracts (left). The presence of NF-kB p65 subunit was examined in the nuclear extracts of T98G, T98G SR, U87 and U87SR by western blotting. Cells were left untreated or were treated with $500 \mathrm{U} / \mathrm{ml}$ of TNF- $\alpha$ for $30 \mathrm{~min}$. (C) EMSA analysis of NF-kB binding in nuclear extracts of LN18 cells irradiated $\left(2.13 \mathrm{~J} / \mathrm{cm}^{2}\right)$ after a 3h-pretreatment with 5ALA in the presence or absence of BAY. Cells were harvested at various times post-irradiation (pi). $\mathrm{NI}=$ cells treated with 5-ALA but not exposed to light.

Fig. 2 : NF-KB inhibition increases glioblastoma cell death after 5-ALA-PDT. Survival of LN18 and LN18 SR (top); of U87 and U87 SR (bottom) irradiated with different light doses pretreated or not with BAY - was determined by trypan blue exclusion $24 \mathrm{~h}$ after photosensitization. $\mathrm{NI}=$ cells treated with 5 -ALA but not exposed to light. Data are mean \pm standard deviation of results of three independent experiments. ( ${ }^{*} p<0.05,{ }^{* *} p<0.01$, t-test).

Fig. 3 : 5-ALA-PDT induce incomplete apoptosis in glioblastoma and NF- $\kappa B$ is pro-apoptotic in this context. (A) Caspase-3 cleavage was assessed in LN18 (pretreated or not BAY) and LN18 SR total extracts harvested at various times post-PDT $\left(2.13 \mathrm{~J} / \mathrm{cm}^{2}\right)$ by Western Blotting (top left). The level of caspase-3 cleavage induced by 5-ALA-PDT at 4 h post-irradiation (pi) was compared to that obtained in HeLa treated with $1 \mu \mathrm{M}$ staurosporine (STS) for $4 \mathrm{~h}$ (top right). $\beta$ actin and $\beta$-tubulin are used as loading controls. Caspase-3 enzymatic activity was measured in the same total extracts (bottom). Data are mean \pm standard deviation of results of three independent experiments. ( ${ }^{*} \mathrm{p}<0.05,{ }^{* * *} \mathrm{p}<0.001$, t-test). (B) DNA fragmentation was assessed by a DNA laddering experiment performed on LN18 cells at various times post-PDT $\left(2.13 \mathrm{~J} / \mathrm{cm}^{2}\right)$ and on cells treated with $2 \mu \mathrm{M}$ daunomycin for $24 \mathrm{~h}$ (Dauno) or $2 \mu \mathrm{M}$ staurosporine for $4 \mathrm{~h}$ (STS). The positive control was U937 cells treated with $4 \mu \mathrm{g} / \mathrm{ml}$ 
camptothecin for 3h. Scale bar $=40 \mu \mathrm{m}$. (C) DNA fragmentation was visualized by a TUNEL experiment, nuclei were stained with Draq5. Cells were fixed $24 \mathrm{~h}$ after 5 -ALA-PDT $\left(2.13 \mathrm{~J} / \mathrm{cm}^{2}\right)$. Cells treated with DNAse I $(10 \mathrm{U} / \mathrm{ml})$ were used as a positive control. (D) Caspase-3 cleavage, CIAP-1 and XIAP expression were assessed by western blot on cells treated or not with 250 or $500 \mathrm{nM}$ BV6 Smac mimetic. BV6 was added 3 hours prior to irradiation $\left(2.13 \mathrm{~J} / \mathrm{cm}^{2}\right)$ and was left on cells until their harvest 4 hours after photosensitization. $\beta$-tubulin is used as a loading control. $\mathrm{NI}=$ cells treated with 5-ALA but not exposed to light.

Fig. 4 : NF-KB inhibition increases 5-ALA-PDT-induced necrosis. (A) Lactate-dehydrogenase activity was measured at various times post-PDT $\left(2.13 \mathrm{~J} / \mathrm{cm}^{2}\right)$ in the supernatants of LN18 (pretreated or not with BAY) and LN18 SR. Data are mean \pm standard deviation of results of three independent experiments. $\left({ }^{*} \mathrm{p}<0.05,{ }^{* *} \mathrm{p}<0.01\right.$, t-test). (B) Necrotic cells were visualized by a propidium iodide staining experiment. Cells were fixed $2 \mathrm{~h}$ after ALA-PDT (2.13 $\left.\mathrm{J} / \mathrm{cm}^{2}\right) . \mathrm{NI}=$ cells treated with 5-ALA but not exposed to light. Scale bar $=40 \mu \mathrm{m}$.

Fig. 5 : 5-ALA-PDT leads to an increased autophagic flux in glioblastoma cells. (A) LC3-I, LC3-II and $\beta$-actin levels were assessed by western blot in LN18 cells total extracts harvested at various times post irradiation (top). Confocal microscopy images showing the distribution of eGFP-LC3 in LN18 eGFP-LC3 cells at $4 \mathrm{~h}$ and $24 \mathrm{~h}$ after irraditation (pi). Scale bar $=20 \mu \mathrm{m}$ (middle). The percentage of autophagic cells presenting a punctuate distribution of eGFPLC3 protein was evaluated in LN18 eGFP-LC3 cells at various times post-irradiation (bottom). Data are mean \pm standard deviation and are representative of three independent experiments. $\left({ }^{* *} p<0.01,{ }^{* * *} p<0.001\right.$, t-test). (B) LC3-I, LC3-II and $\beta$-actin levels were examined by western blot in LN18 - pretreated or not with $100 \mathrm{nM}$ bafilomycin Al (Baf) - at various times post-irradiation $\left(2.13 \mathrm{~J} / \mathrm{cm}^{2}\right) . \mathrm{NI}=$ cells treated with 5 -ALA but not exposed to light. (C) S6K phosphorylation as well as S6K, LC3-I, LC3-II and $\beta$-actin levels were examined by western blot in LN18 (pretreated or not BAY) and LN18 SR total extracts harvested at various times post-PDT $\left(2.13 \mathrm{~J} / \mathrm{cm}^{2}\right)$.

\section{Fig. 6 : Inhibition of autophagy induces a further sensitivity to 5-ALA-PDT induced necrosis.} Inhibition of autophagy was obtained by transfecting LN18 cells with an ATG7 siRNA. Nontransfected cells (NTr) or cells transfected with a control siRNA were used as controls. The 
indicated treatments were performed 48 hours post-transfection. (A) Levels of ATG7 and $\beta$ actin in LN18 cells were assessed by western blot (left). LC3-I, LC3-II and $\beta$-actin levels were assessed by western blot in LN18 cells total extracts harvested at various times post irradiation. The ratio between LC3-II and LC3-I was then quantified and normalized using $\beta$-actin level (right). (B) Lactate-dehydrogenase activity was measured at various times post-PDT (2.13 $\mathrm{J} / \mathrm{cm}^{2}$ ) in the supernatants of LN18 cells. The supernatants were harvested at the indicated times after irradiation $\left(2.13 \mathrm{~J} / \mathrm{cm}^{2}\right)$ (top). Data are mean \pm standard deviation and are representative of three independent experiments. ( ${ }^{*} p<0.05,{ }^{* *} p<0.01$, t-test). Necrotic cells were visualized by a propidium iodide staining experiment. Cells were fixed $2 \mathrm{~h}$ after ALA-PDT $\left(2.13 \mathrm{~J} / \mathrm{cm}^{2}\right)$. Scale bar $=40 \mu \mathrm{m}$ (bottom). (C) Lactate dehydrogenase activity was measured in LN18 cells supernatants at the indicated times post-irradiation $\left(2.13 \mathrm{~J} / \mathrm{cm}^{2}\right)$. Cells were either left untreated or were pretreated with $10 \mu \mathrm{M}$ BAY 30 min prior to photosensitization. Data are mean \pm standard deviation and are representative of three independent experiments. $\left({ }^{*} \mathrm{p}<0.05,{ }^{* * *} \mathrm{p}<0.001, \mathrm{t}\right.$-test). $\mathrm{NI}=$ cells treated with 5 -ALA but not exposed to light. (D) Caspase-3 and $\beta$-actin (upper left) as well as ATG7 and $\beta$-actin levels (upper right) were studied by western blot in LN18 total extracts at the indicated times post-irradiation (2.13 $\mathrm{J} / \mathrm{cm}^{2}$ ). Caspase-3 enzymatic activity was measured in the same total extracts (bottom). 
Figure 1

Click here to download high resolution image

Figure 1
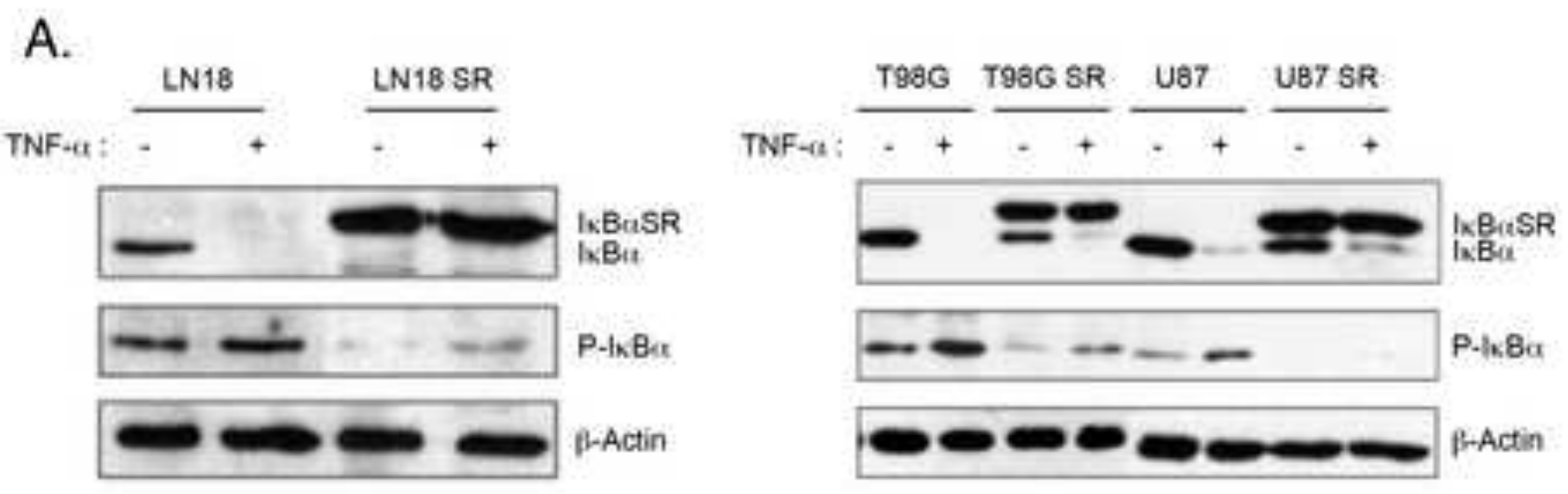

B.
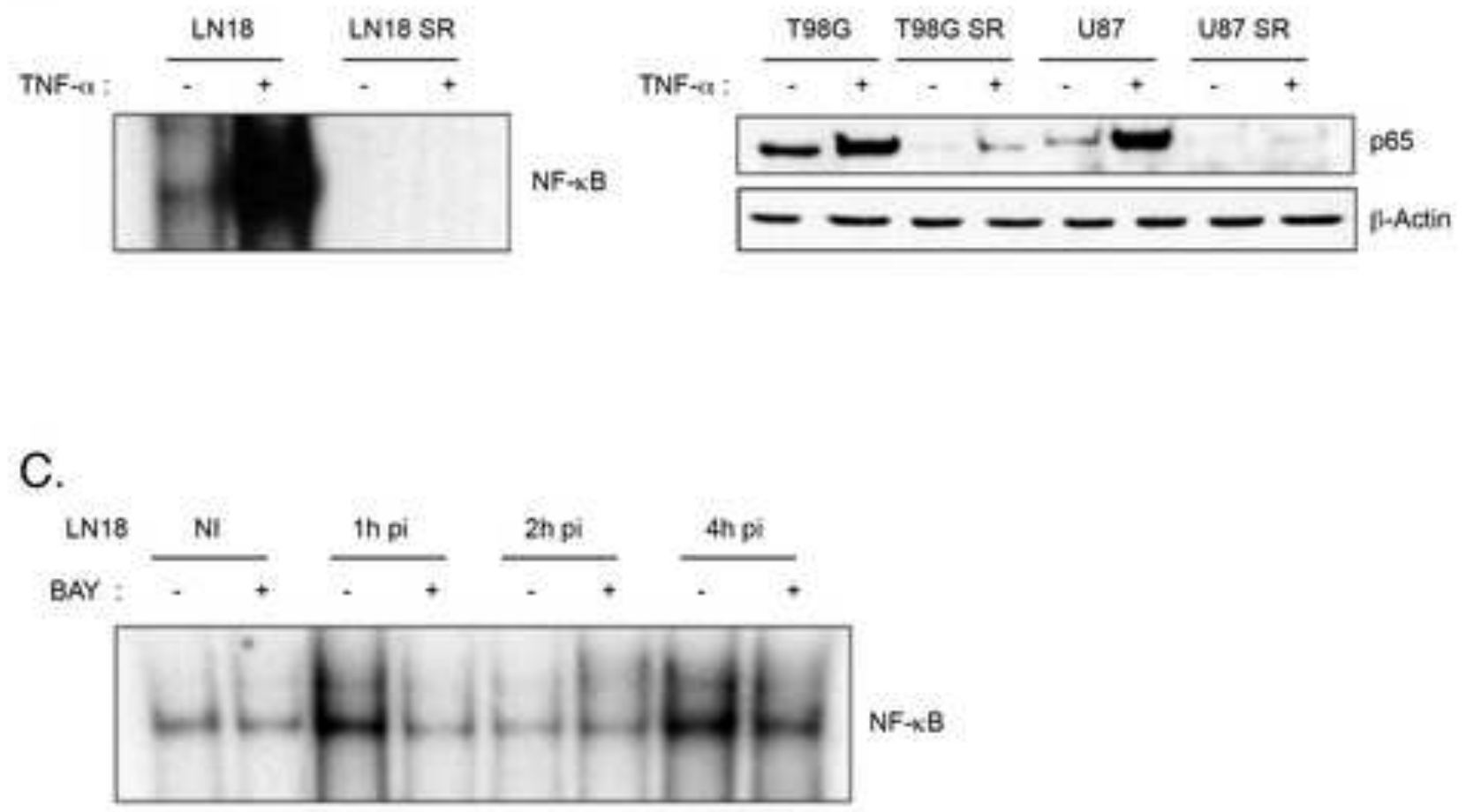
Figure 2

Click here to download high resolution image

Figure 2
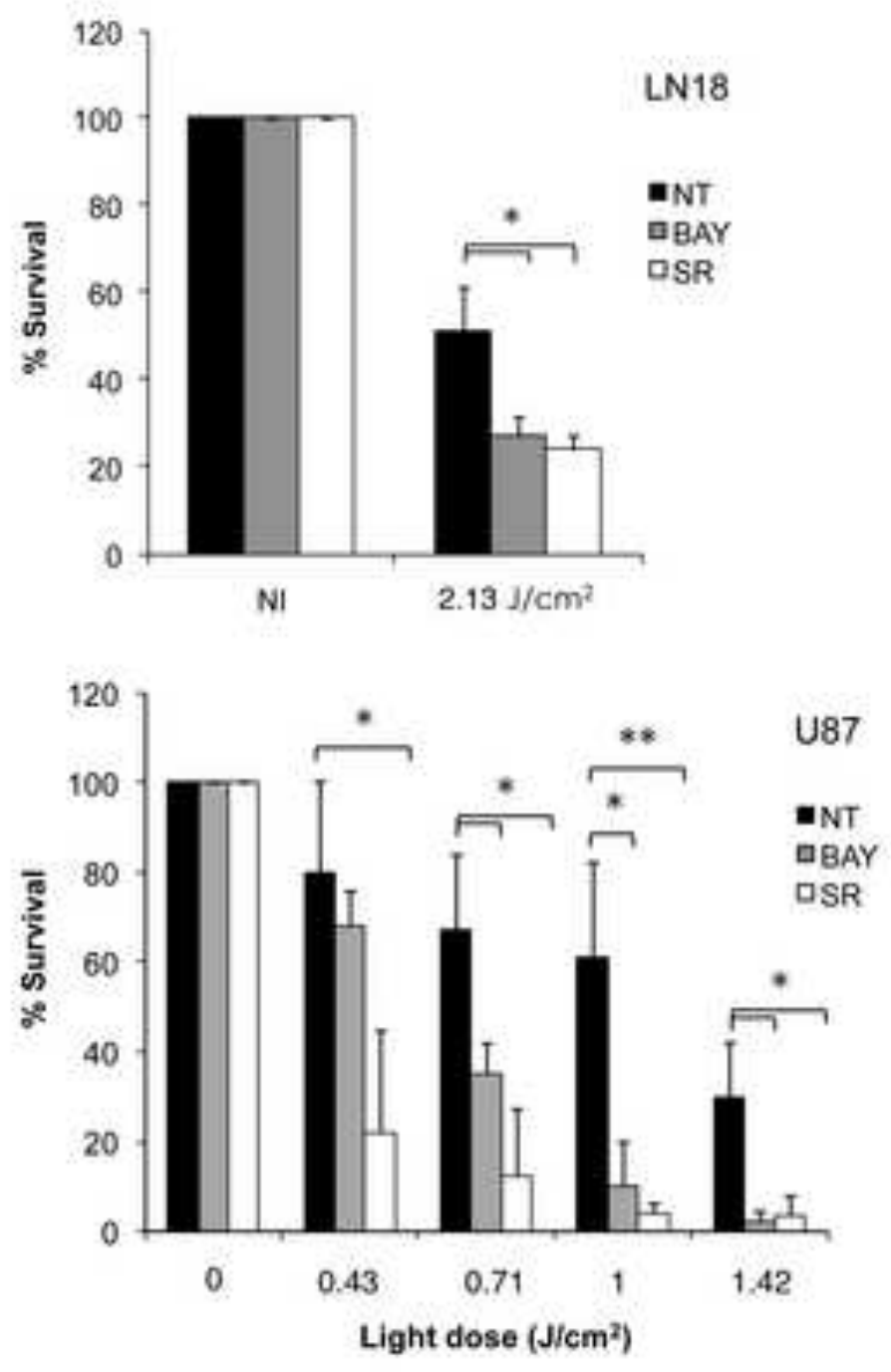
Figure 3

ACCEPTED MANUSCRIPT

Click here to download high resolution image

Figure 3

A.

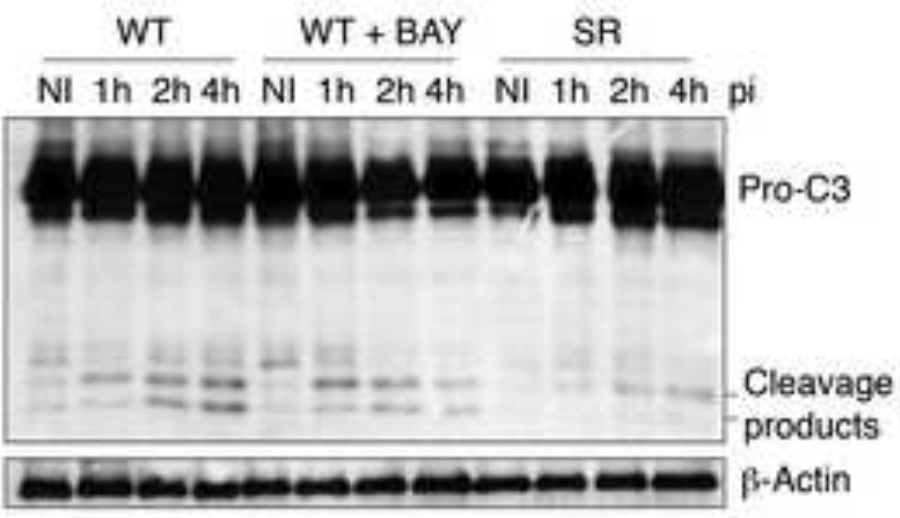

HeLa $\frac{\text { LN18 }}{\text { STS NI } 4 \mathrm{~h} \mathrm{pi}}$

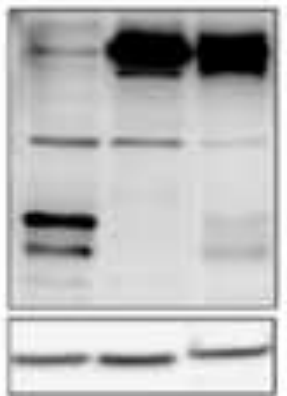

Pro-C3

Cleavage

products

$\beta$-Tubulin

B.

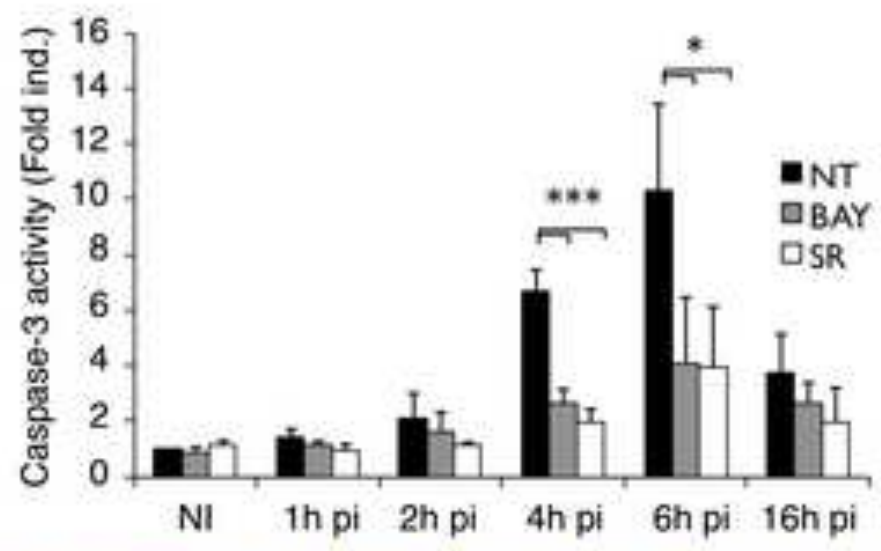

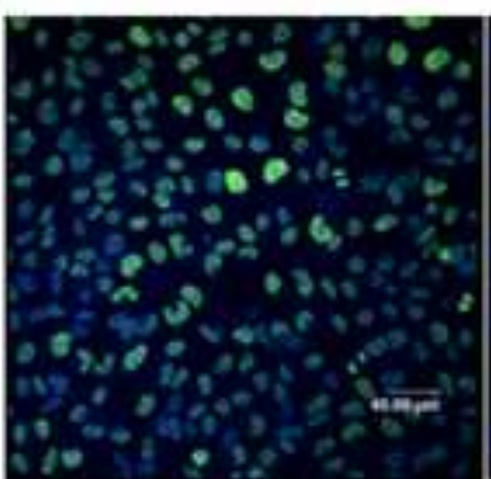

+ DNAse 1

C.

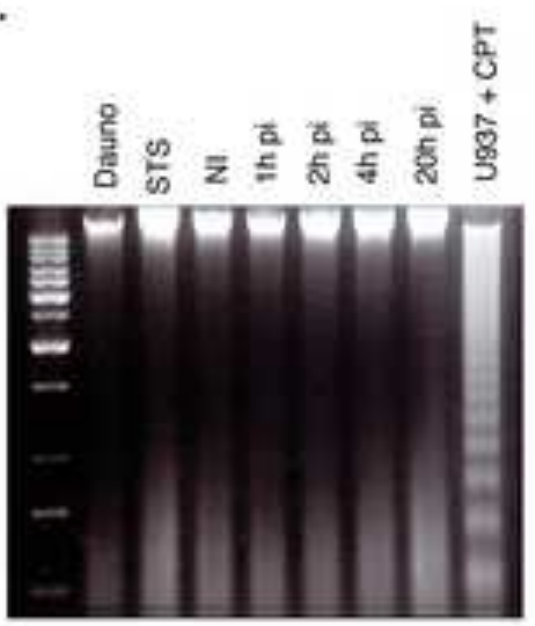

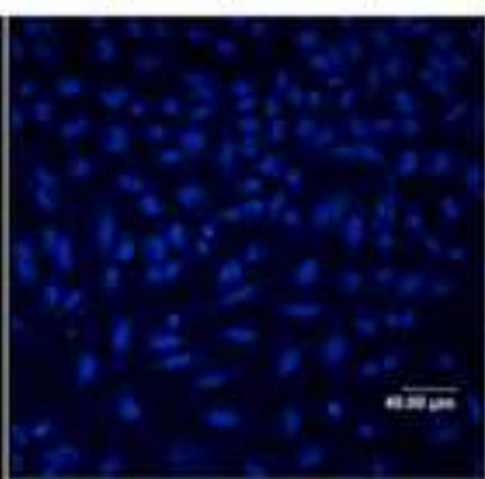

NI

D.

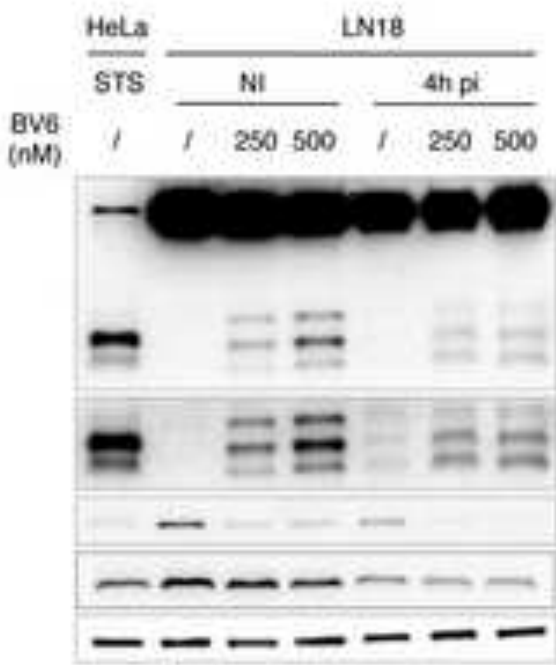

pro C3

Cloavage products

Cleavage

products (ibroir exponure) CIAP-1 xLAP E.Tubualn 
Figure 4

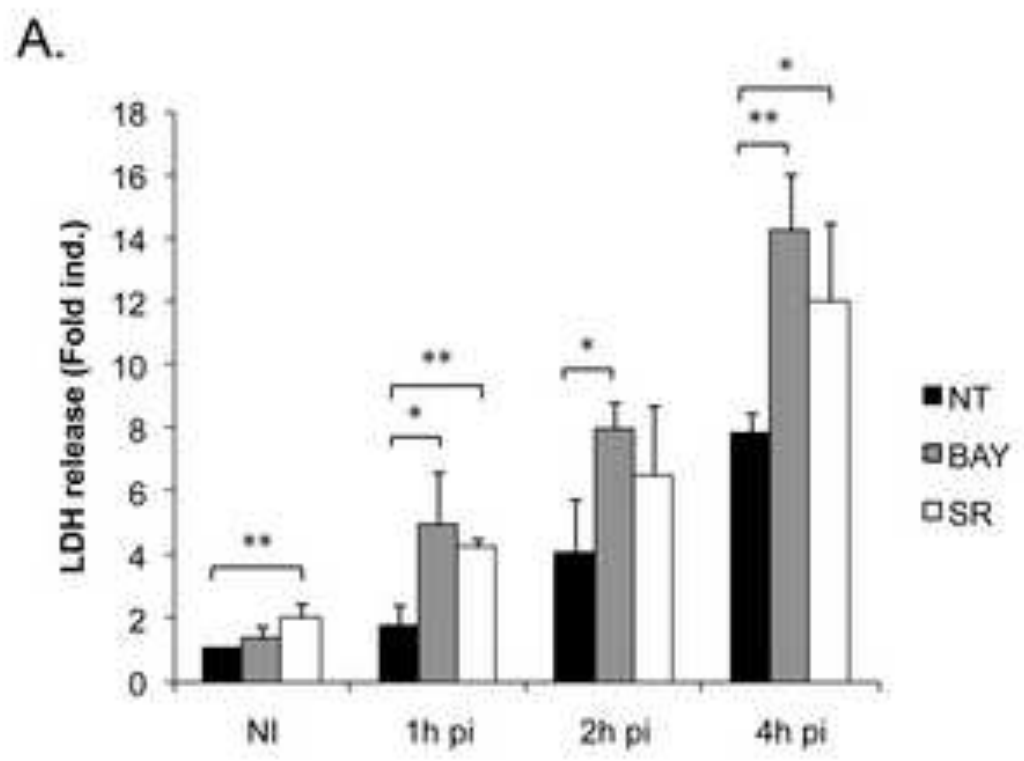

B.

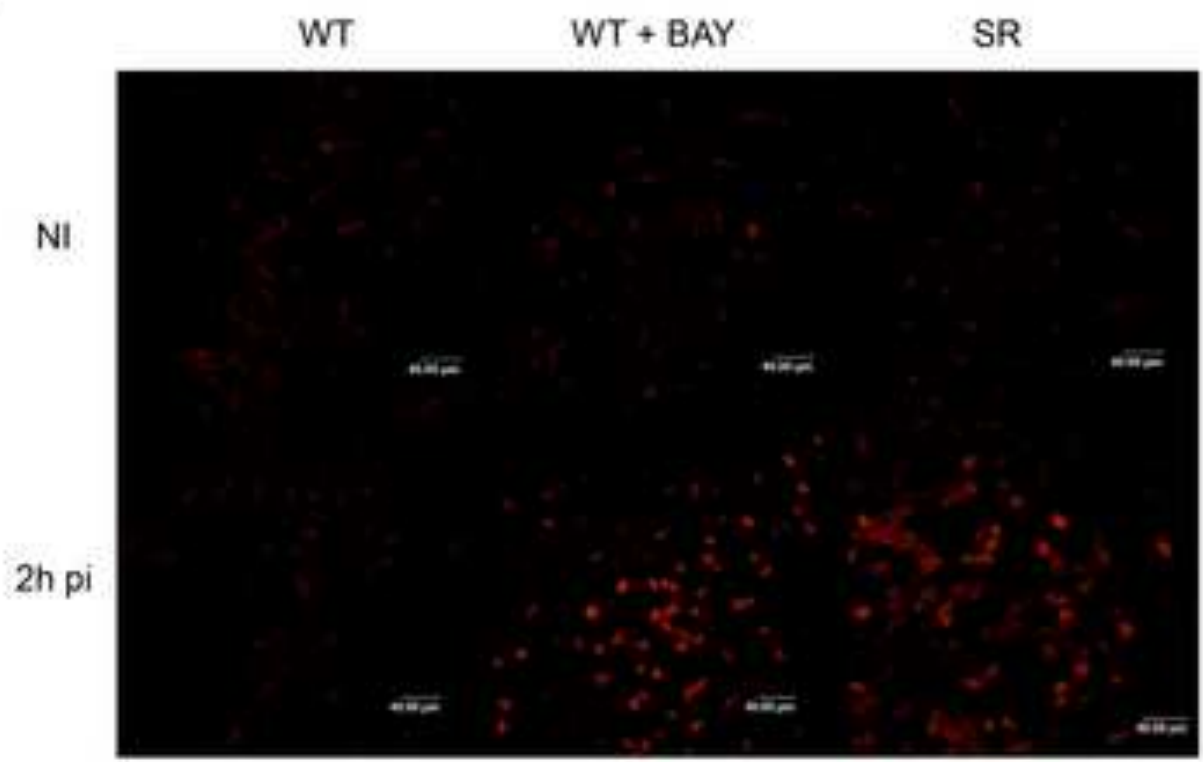


Figure 5

Click here to download high resolution image

Figure 5

A.

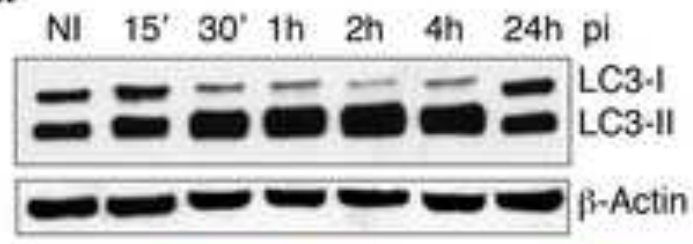

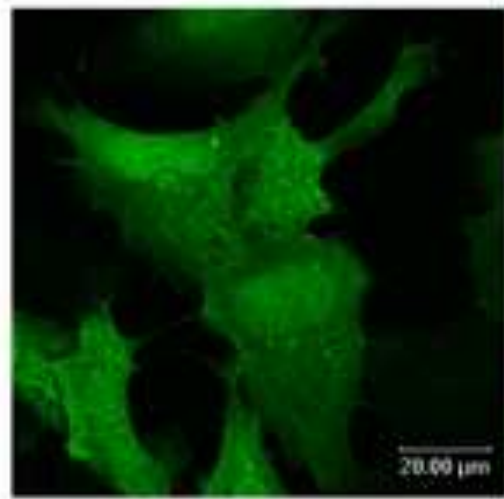

NI

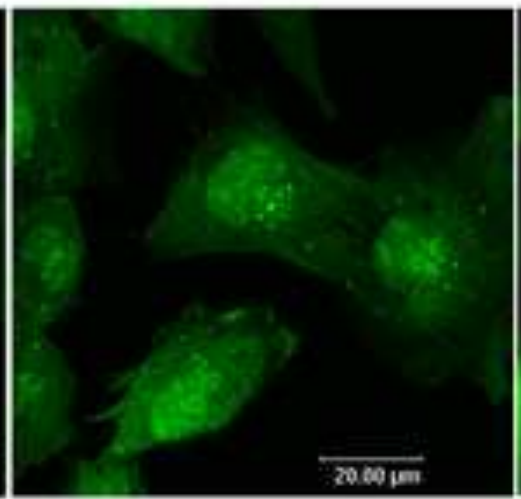

4h pi

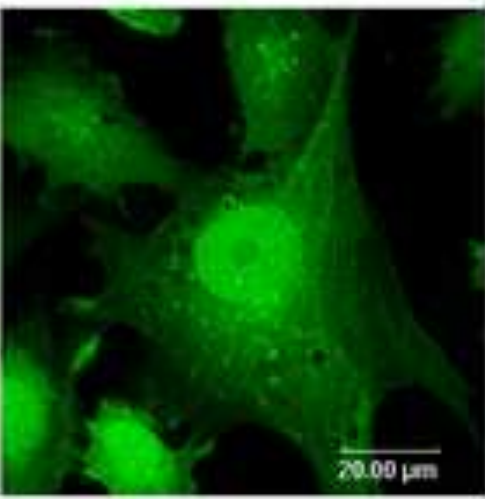

24h pi

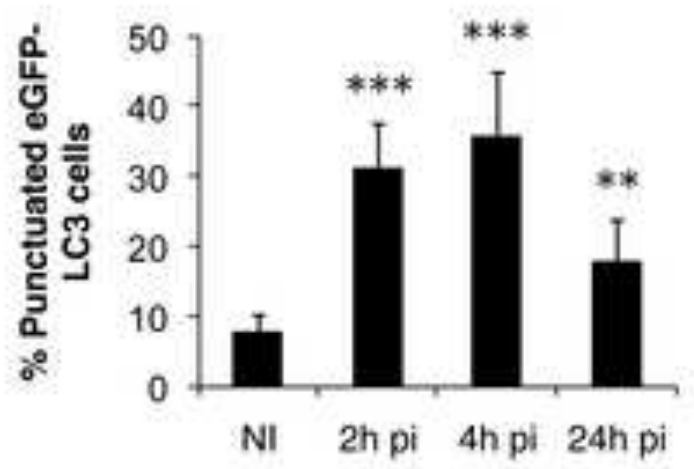

B.

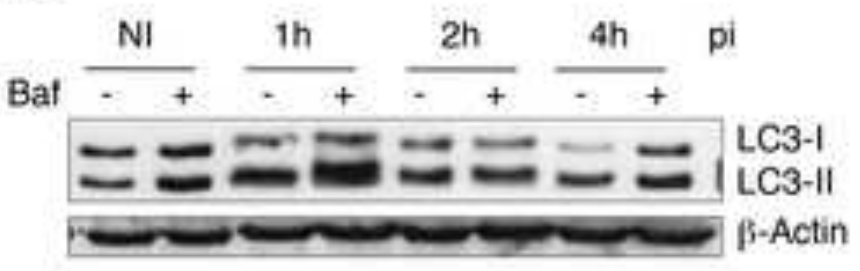

C.

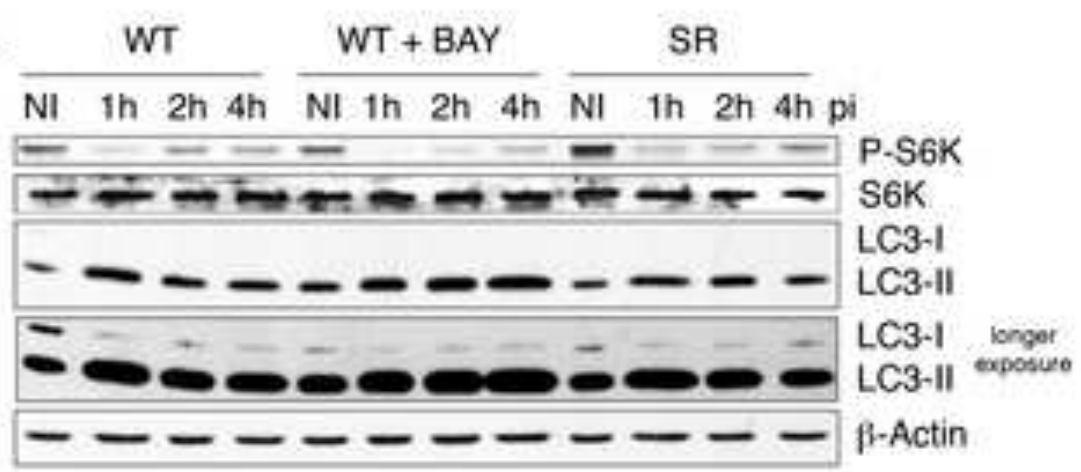


Figure 6

A.

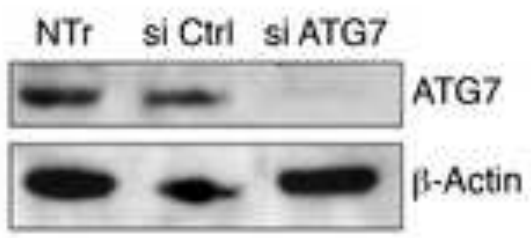

B.
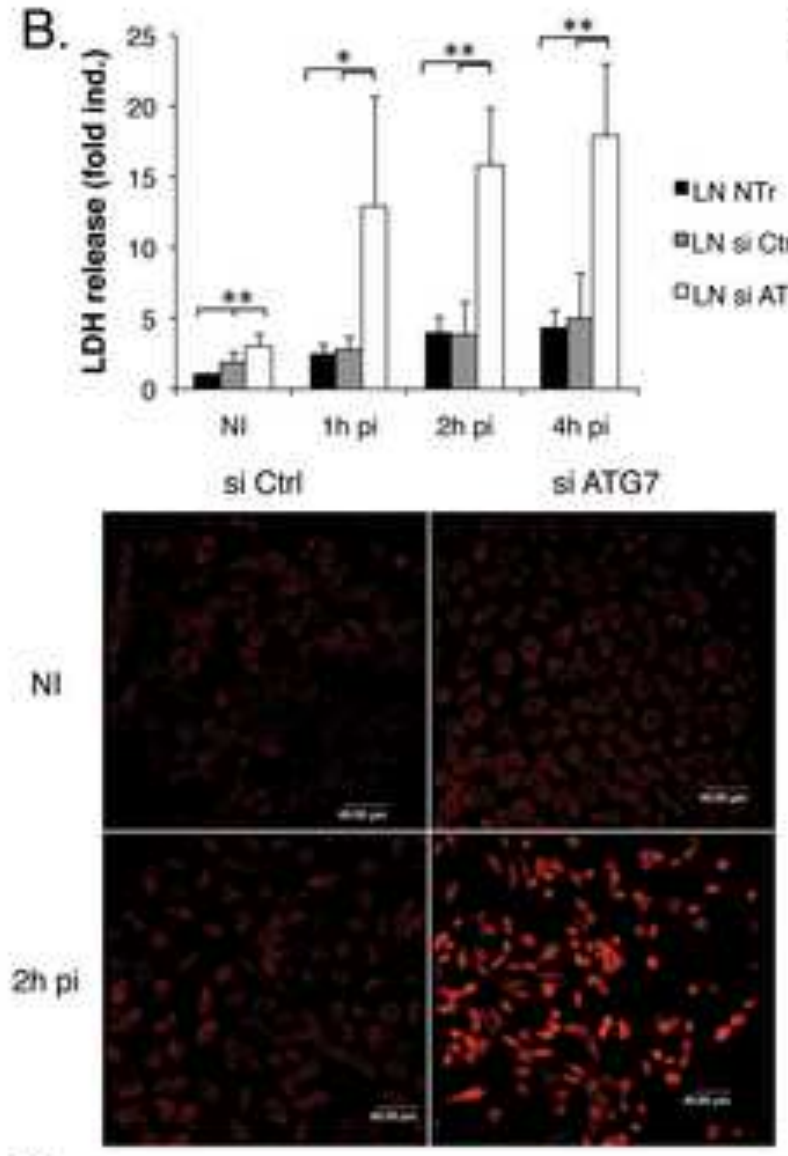

D.

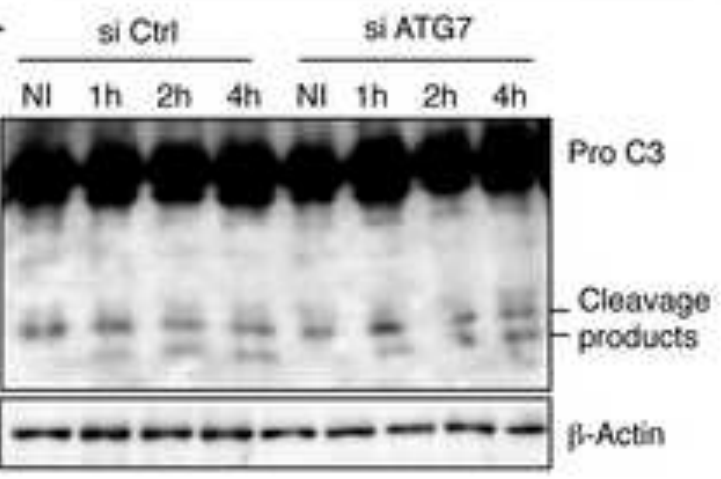

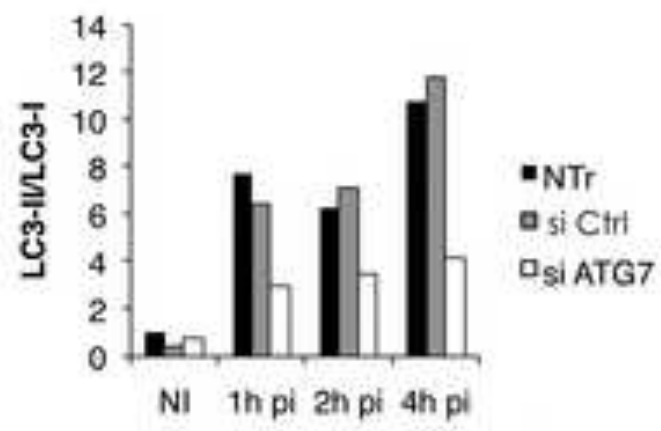

C.

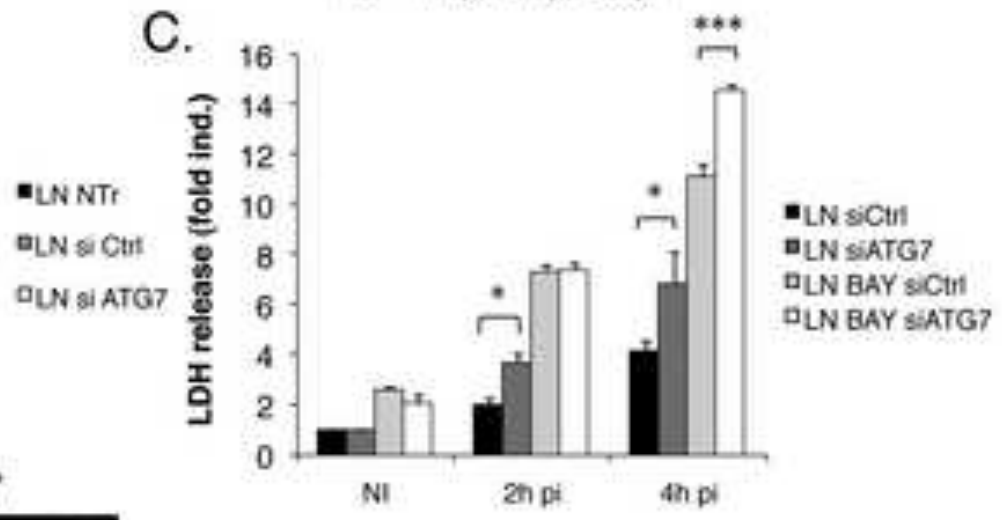

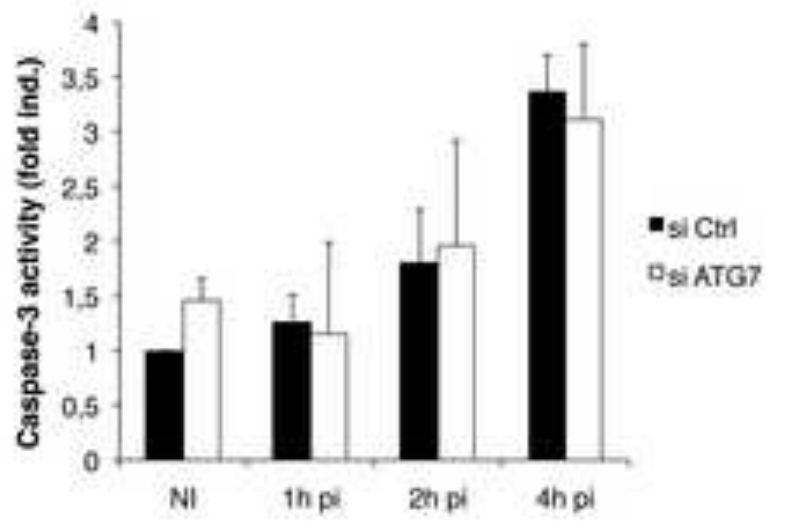

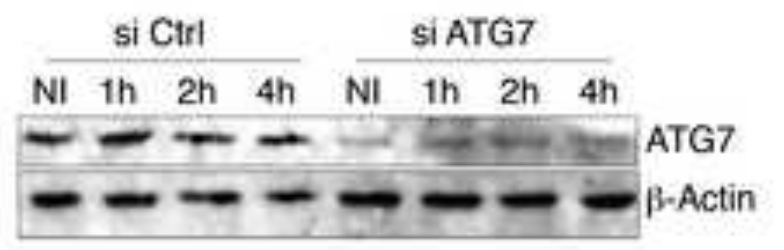




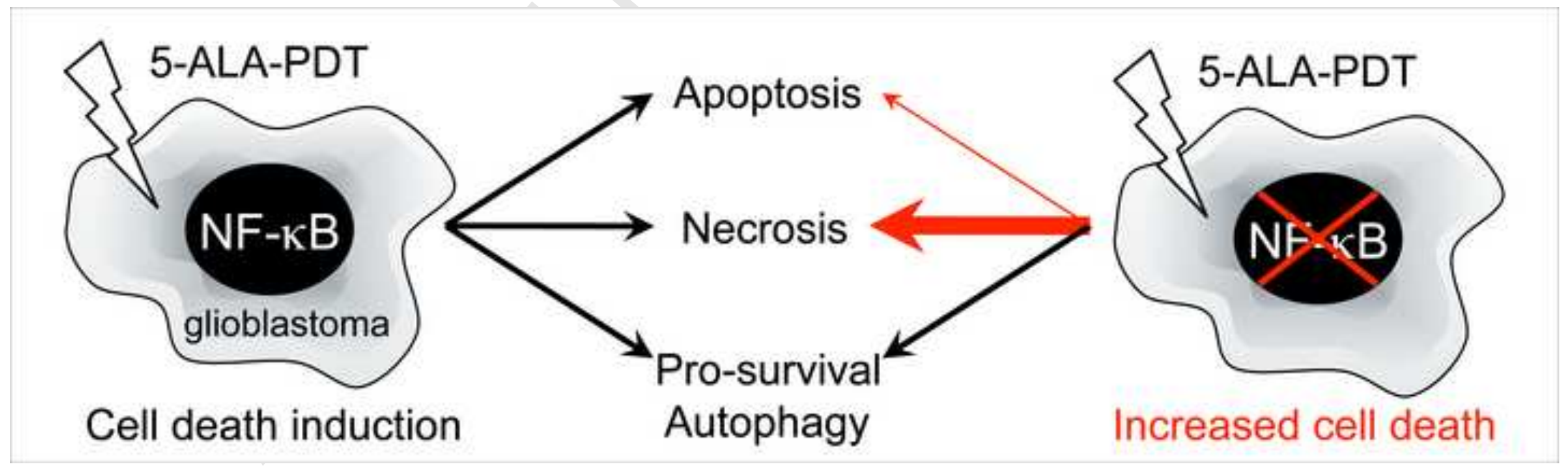

